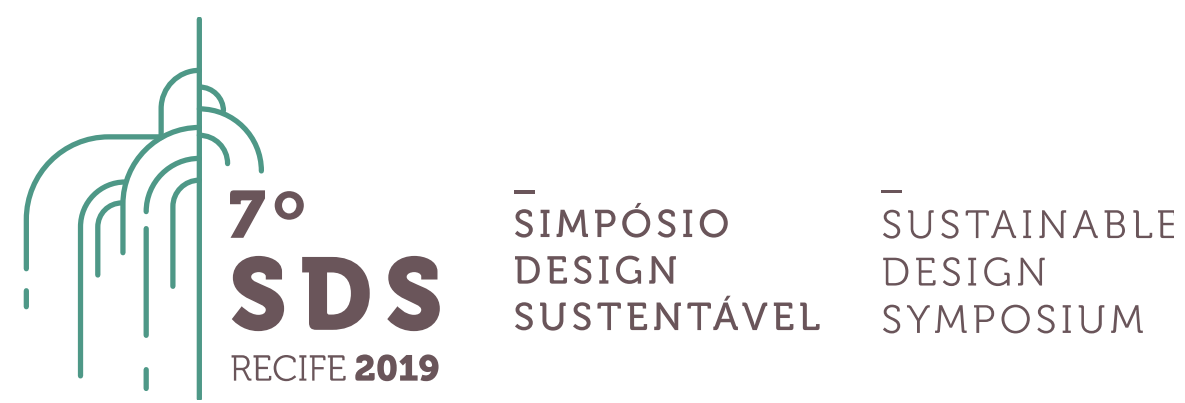

\title{
Design e artesanato: uma prática para valorização cultural e geração de renda na comunidade de Araçuaí
}

\author{
Rita de Castro Engler ${ }^{1}$, Viviane da Cunha Melo ${ }^{2}$, Nadja Maria Mourão ${ }^{3}$ \\ ${ }^{1}$ Universidade do Estado de Minas Gerais, CEDTec, rita.engler@gmail.com \\ ${ }^{2}$ Universidade do Estado de Minas Gerais, CEDTec, vivi_melo15@hotmail.com \\ ${ }^{3}$ Universidade do Estado de Minas Gerais, CEDTec, nadjamourao@gmail.com
}

\begin{abstract}
Resumo $O$ objetivo deste trabalho é identificar como a atuação do design em parcerias com grupos de produção artesanal, pode favorecer o desenvolvimento de produtos, com valor mercadológico. Acredita-se que este modelo de atividade possa contribuir para o aumento da geração de renda em comunidades que se encontram às margens da sociedade. Por delimitação da pesquisa, apresenta-se um recorte e a análise do desenvolvimento de Oficinas em Design, para um grupo de artesãos da Cooperativa Dedo de Gente, da comunidade de Araçuaí, em Minas Gerais. A metodologia abordou uma revisão da literatura, em pesquisa qualitativa de natureza aplicada. As oficinas são o objeto de estudo deste artigo. Observou-se que o design pode contribuir com o artesanato executando práticas para melhoria estética do produto artesanal, de forma a valorizar a cultura, a identidade $e$ as tradições da comunidade. O desenvolvimento das Oficinas de Design e Artesanato exerceu um impacto significativo no sistema de produção da fabriqueta de resíduos de madeira da Cooperativa. Foi possível observar que as atividades da Oficina de Identidade, cultura material e imaterial proporcionaram conhecimentos do território, levando os participantes a valorizarem as características locais. A conclusão da oficina em processo criativo apresentou, na criação de novos produtos, que as metodologias apresentadas e adotadas evidenciam inovação, além de congregar e revelar os aspectos socialmente relevantes da comunidade.
\end{abstract}

Palavras-chave. Design, artesanato, valorização cultural, empreendedorismo, Cidade de Araçuaí.

\section{Introdução}

Nas últimas décadas, percebe-se a ampliação do campo do design para abordagens que vão além de projetar produtos e serviços. Sua área de atuação evoluiu para setores diversificados em modelos sistêmicos, participativos, do tecnológico ao humano. Este novo caminho que o design vem percorrendo, surgiu da necessidade de contemplar questões de natureza social, ambiental e cultural, que se tornaram latentes na sociedade. Pazmino (2007) afirma que os 
problemas sociais compõem a realidade vivenciada nas comunidades, sejam elas grandes metrópoles ou grupos rurais. As intensidades dos problemas são diferentes de acordo com a região, porém, nenhum profissional deve ignorá-los, muito menos o designer.

O design busca propor soluções para temas complexos que necessitam de novos olhares e novas formas de conexões, envolvendo produtos, serviços, sistemas e comunicação. De forma conjunta e sustentável, a prática do designer contribui para a ampliação de seu papel como agente transformador na sociedade e ressalta a importância do desenvolvimento de relações transversais, com as mais diversas áreas. "O design existe para todos e, portanto, deve ser divulgado, levado a locais onde ele ainda não existe de maneira formal, tornando-o acessível ao maior número possível de pessoas" (ENGLER et al., 2010, p.33).

O design pode ser o elo de mediação entre diversas áreas como a tecnologia, marketing, mercado, consumo e estética, com o intuito de concretizar o entendimento de sua ação abrangente, expressando o seu diferencial (BORGES, 2003). Dessa forma, o design estende suas fronteiras produtivas, tecnológicas e econômicas, abrangendo aspectos relacionados ao "ser humano ético, social, cultural e ambiental, em um sistema de rede aprimorando a função do design" (MOURÃO; MARTINS, 2014, p.26).

Nota-se um aumento da atuação de designers em comunidades ou grupos de produções artesanais, com o objetivo de colaborar no desenvolvimento dos produtos e ampliar seu acesso ao mercado. Produtos utilitários e artísticos tem a capacidade de revelar a identidade e os saberes locais valorizando o território e sua cultura. "Como uma forma de manifestação cultural popular, o artesanato revela as tradições e características de um povo" (SOUZA, 2015, p.3).

A expansão da atuação do designer no âmbito social conduz o profissional a "ações projetuais orientadas a modos de viver além de consumir e produzir, valorizando a experiência e as emoções de uso e apropriação de espaços, bens e serviços" (MANZINI; MERONI, 2007, p.21). Engler e Mourão (2017) e Niemeyer (2007) concordam na afirmativa que design pode e deve promover a reflexão por parte dos artesãos quanto a seus valores culturais e sociais, melhorias em seu processo produtivo e ativação do sentimento de pertencimento. Quanto mais informação tiver o produto, mais forte é a sua identidade.

Nas últimas décadas, as crises econômicas e políticas que o país enfrenta, não colaboraram com o desenvolvimento do setor de artesanato no Brasil. Contudo, ainda assim, ele permanece em uma posição de destaque na economia nacional. O Mercado do artesanato possui em média \$ 28 bilhões por ano de faturamento, emprega 8 milhões de pessoas e cresce a cada ano (SEBRAE, 2019). O artesanato é uma das alternativas para diminuir o alto índice de desemprego atual, pois permite atuação de pessoas com habilidades diversas e pouco investimento inicial. Existe uma grande diferença entre a riqueza e o desenvolvimento da nação, conforme Smith (2003).

Para o presente estudo, buscou-se identificar como a atuação do design em parcerias com grupos de produção artesanal, pode favorecer o desenvolvimento de produtos (com valor mercadológico). Acredita-se que este modelo de atividade pode contribuir para o aumento da geração de renda em comunidades que se encontram às margens da sociedade. Espera-se contribuir para reflexões acerca do artesanato e o relacionamento com o design, quanto a necessidade de executar práticas voltadas para o aperfeiçoamento e melhorias ao produto artesanal, valorização da cultura e tradição regional e atividades que estimulem a capacidade criativa do artesão para a competividade dentro de um modelo capitalista no qual a concorrência de mercado se tornou global.

Por delimitação da pesquisa, apresenta-se um recorte e a análise do desenvolvimento de oficinas em design com um grupo de artesãos da Cooperativa Dedo de Gente da comunidade de 
Araçuaí, em Minas Gerais. As oficinas são parte do estudo de caso de pesquisa científica de mestrado, atendendo ao Programa de Pós-Graduação da Universidade do Estado de Minas Gerais. A metodologia abordou uma revisão da literatura, em pesquisa qualitativa de natureza aplicada. As oficinas são o objeto de estudo deste artigo.

\section{Design e artesanato}

O artesanato brasileiro apresenta uma grande diversidade, seja pelo tipo de matéria-prima utilizada, pela técnica, pelo produto que é confeccionado ou pelas diversas realidades vividas pelos artesãos. Os produtos tendem a apresentar, em pequenas quantidades ou de forma exclusiva, uma carga simbólica e identitária. Tais características colocando-o em um patamar geram um valor agregado ao produto artesanal de exclusividade, de diferenciação.

A atividade artesanal proporciona diversos benefícios sociais para o artesão, entre eles podese citar a realização pessoal, promoção da inserção da mulher e do adolescente em atividades produtivas, fixação do artesão em seu local de origem, elevação da autoestima, alternativa de geração de renda frente ao desemprego e à carência em qualificação, dentre outros aspectos. A valorização cultural está presente na atividade artesanal e é através dela, que a origem do artesão é transmitida de geração em geração, dando significado ao artesanato e indicando para o artesão o seu lugar no mundo (SEBRAE, 2004).

Segundo Canclini (2000) o aumento da atividade artesanal em algumas regiões está relacionado com inúmeras transformações econômicas e sociais que a sociedade vem passando. Dessa forma, a busca da sociedade pós-industrial por produtos menos massificados, o aumento e a valorização das feiras de artesanato e objetos, movimentos de incentivo a compra por produtos locais ou de origem certificada, bem como à sua divulgação pelos meios de comunicação de massa. Todo este panorama faz com que o artesanato esteja em voga e consequentemente traz uma série de benefícios.

Crocco (2000) destaca que os projetos que aconteceram no Brasil no início do século XXI de resgate e valorização do artesanato evidenciam a importância socioeconômica e cultural que este ramo tem para o país. Cada vez mais, têm-se tornado comum a atuação de designers em comunidades/grupos de produções artesanais, com o objetivo de colaborar no desenvolvimento dos produtos e ampliar seu acesso ao mercado. As intervenções de design em grupos de produção artesanal têm como objetivo tornar a produção artesanal economicamente viável e seguir às exigências de mercado com relação à estética, qualidade, ergonomia, etc; tornando assim os produtos comercialmente atraentes. Além do incentivo a promoção de novas atitudes pelo artesão frente ao seu trabalho.

Há, portanto, uma mudança de valores territoriais e identidade local, pois muito do que hoje está sendo recuperado passa pelas mãos do designer. "Trata-se de um trabalho que redescobre o antigo fazer artesanal e o orienta - sem ferir em sua expressão original - no sentido de torná-lo adequado ao mercado". O Sebrae tem prestado contribuições relevantes neste processo em comunidades brasileiras. Contudo, é um desafio aos designers “...identificar o diferencial, as características desse design, é criar produtos capazes de encontrar um mercado local, nacional e internacional" (FRANÇA, 2005, p.11). Neste contexto, o design tem um papel importante, na medida em que abrange atividades de planejamento, decisões e práticas, incluindo estudos de produtos de mercado, que contribuem para o desenvolvimento do artesanato local. Este ponto também é levantado por Cavalcanti et al. (2013), que acredita que as metodologias de design podem facilitar a interlocução entre design e artesanato na busca por soluções criativas, duradouras e de impacto positivo. 
Tanto a criatividade quanto as ações colaborativas não podem ser impostas às comunidades/grupos de artesãos, pois cada intervenção externa que é realizada coloca em risco o equilíbrio daquele grupo (MANZINI, 2008). Para Borges (2011), o designer ao se aproximar do artesão deve-se colocar no mesmo nível buscando um relacionamento de forma equivalente e respeitosa. "O artesanato é um patrimônio inestimável que nenhum povo pode se dar ao luxo de perder. Mas esse patrimônio não deve ser congelado no tempo. Congelado, ele morre. E é na transformação respeitosa que entra o papel dos designers" (BORGES, 2003, p.68).

Os caminhos futuros para o artesanato passam pelo relacionamento com o design, cada um contribuindo com suas expertises, tendo como objetivo a geração de renda, o desenvolvimento local, a valorização da tradição artesanal e a produção de objetos com maior valor agregado e de mercado. Como colocado por Engler e Mourão (2017, p.309) "devemos acreditar e investir em novas possibilidades que apontem soluções para um futuro com melhor qualidade de vida para todos".

Dessa forma, acredita-se que, na sociedade atual, é necessária a atuação dos designers junto ao artesanato através do diálogo entre diversas áreas do conhecimento para que seja possível desenvolver produtos de qualidade, atendendo as reais necessidades e demandas dos usuários e com valor mercadológico. É função do designer trabalhar a autoestima destas pessoas que muitas vezes se encontram às margens da sociedade promovendo a inclusão social e o desenvolvimento humano. Mourão (2013, p.75) afirma que o "reconhecimento dos potenciais, da capacidade de aprender, criar e inovar" são maneiras de contribuir para elevação da autoestima.

\section{Cooperativa Dedo de Gente}

Conforme site da instituição, a Cooperativa Dedo de Gente foi criada em 1996, em Curvelo, cidade de Minas Gerais, reunindo diversas unidades de produção, conhecidas como "fabriquetas", que são formadas e dirigidas por jovens em situação de vulnerabilidade. Hoje a Cooperativa tem unidades em três cidades mineiras: Curvelo, Araçuaí e Raposos.

O projeto, liderado pelo educador Tião Rocha, nasceu como consequência de um processo educativo iniciado em 1984 pelo CPCD - Centro Popular de Cultura e Desenvolvimento, organização que tem como razão de ser a promoção da educação popular e o desenvolvimento comunitário a partir da cultura, tomada como matéria-prima de ação institucional e pedagógica.

Nas fabriquetas a criação é feita individual e coletivamente. Quando uma nova peça é criada, todos avaliam e contribuem para melhorar o desenho ou o acabamento. Uma vez por mês, são realizados eventos para estimular a inovação, conhecidos como Dias da Criatividade. As referências dos artesãos são os artistas e a literatura locais, bem como pesquisas da internet, revistas especializadas e eventos da área. As fontes de inspiração também embasaram a escolha do nome da cooperativa (Dedo de Gente), devido à criação manual das peças, feitas por todos os integrantes da cooperativa.

Atualmente, a Dedo de Gente possui dez fabriquetas divididas em unidades: de serralheria, marcenaria, bordados, bambu e arranjos florais. Eles trabalham, ainda, com cartonagem (produção de artefato de cartões), tintas de terra (pintura feita com pigmentos de terras brasileiras), doces e licores, e casinhas de passarinho. Mais de dois mil produtos já foram criados e 200 estão no portfólio permanente da instituição.

Em 2014, a cooperativa Dedo de Gente somava 110 jovens que compõem três unidades nas cidades mineiras de Curvelo, Araçuaí e Raposos. Herdeira desse espírito, a Cooperativa existe para gerar oportunidades inovadoras de desenvolvimento humano e profissional para jovens de Minas Gerais. 


\section{Oficinas de design}

Com a intenção de desenvolver produtos pensando nas questões de identidade, cultura local e criatividade foram desenvolvidas junto ao grupo de artesãos das fabriquetas 'Arte em madeira' e 'Cores da Terra' da Cooperativa Dedo de Gente da comunidade de Araçuaí, duas oficinas e uma expedição fotográfica pela cidade de Araçuaí. Os encontros consistiram em aulas teóricas e atividades práticas. Ao final das atividades os artesãos desenvolveram uma linha de produtos seguindo os preceitos apresentados durantes as oficinas.

As oficinas foram ministradas para um grupo de sete artesãos, cuja idade variava entre 16 a 21 anos de ambos os sexos. O trabalho foi coordenado por uma professora e uma mestranda do curso de Pós-graduação em Design da Universidade do Estado de Minas Gerais - ED. Para uma melhor compreensão sobre os trabalhos realizados, optou-se por relatar as experiências nas oficinas.

\subsection{O método das oficinas}

Utilizou-se durante o desenvolvimento da pesquisa a coleta de dados através da documentação indireta - pesquisa bibliográfica, e da documentação direta - observação qualitativa, participativa, aplicação de questionários, registros fotográficos e entrevistas. Para as oficinas utilizou-se a metodologia de pesquisa-ação, que consiste na análise sobre o contexto da realidade das comunidades envolvidas no projeto (THIOLLENT, 1986). 'Visando à compreensão ampla do fenômeno que está sendo estudado, considera que todos os dados da realidade são importantes e devem ser examinados. $\mathrm{O}$ ambiente e as pessoas nele inseridas devem ser olhados holisticamente [...]' (GODOY, 1995, p. 62).

Para este artigo, executou-se um recorte das ações do design nas oficinas, de forma a analisar a percepção dos participantes, quanto às questões de identidade, cultura material e imaterial e criatividade. Assim, os estudos de revisão bibliográfica foram utilizados, como também relatos das oficinas.

\subsection{Oficina de Identidade, cultura material e imaterial.}

O encontro intitulado como "Identidade, cultural material e imaterial" tinha como objetivo apresentar os conceitos sobre cada um dos termos: identidade, cultura material e cultura imaterial; e fazer com que eles identificassem dentro da própria comunidade e do próprio negócio estes conceitos. Para isso no início da aula foi exposto através da apresentação de slides o conceito de identidade pessoal, identidade social e identidade cultural trazendo exemplos do que seria cada um. Logo após a apresentação foi realizado uma atividade no qual eles deveriam reconhecer as identidades sociais que faziam parte da Cooperativa Dedo de Gente. Com isso, surgiram os termos: sustentabilidade, produção artesanal, cooperativismo, economia solidária, valorização local, criatividade, fazer a mão, dentre outros. Houve um momento de debate para refletir se realmente aquelas identidades definidas por eles estavam incorporadas na cooperativa e se elas estavam comunicando com os clientes.

Após o debate, apresentou-se o conceito de cultura material e imaterial, sendo a cultura material algo que está relacionado com a finalidade ou sentido que os objetos têm para um povo numa cultura. O que é material é físico, é objeto ou artefato e é entendido pelos seres humanos como um legado. A cultura material ainda pode ser dividida em dois grandes grupos "...em bens imóveis como os núcleos urbanos, sítios arqueológicos e paisagísticos e bens individuais; e móveis como coleções arqueológicas, acervos museológicos, documentais, bibliográficos, arquivísticas, videográficos, fotográficos..." segundo o Instituto do Patrimônio Histórico e Artístico Nacional - 
IPHAN $^{1}$. E a cultura imaterial é algo que possui um grau de abstração, ou seja, algo que não é concreto. Segundo IPHAN ${ }^{2}$ a cultural imaterial seria “...práticas e domínios da vida social que se manifestam em saberes, ofícios e modos de fazer; celebrações; formas de expressão cênicas, plásticas, musicais ou lúdicas; e nos lugares (como mercados, feiras e santuários que abrigam práticas culturais coletivas)." Envolvem os conhecimentos que são transmitidos de geração a geração.

Após apresentação dos conceitos aos artesãos, com exemplos da cultura material e imaterial brasileira, foi realizado uma atividade em grupo no qual os artesãos deveriam identificar e classificar cultural material e imaterial da cidade de Araçuaí, conforme mostram as figuras 03 e 04. Esta atividade foi definida pelos próprios artesãos como bastante proveitosa, pois foi um momento que eles perceberam os valores culturais do próprio território e constataram a riqueza que a comunidade tem culturalmente. Também foi um momento de troca e união do grupo, onde muitos relembraram histórias e compartilharam momentos que viveram durante as festas tradicionais da cidade, os "causos", as histórias de pessoas caricatas da cidade, a culinária típica da região, os aspectos da vegetação, entre outros.

Figura 03 e 04: artesãos reunidos realizando atividade e imagem da atividade.

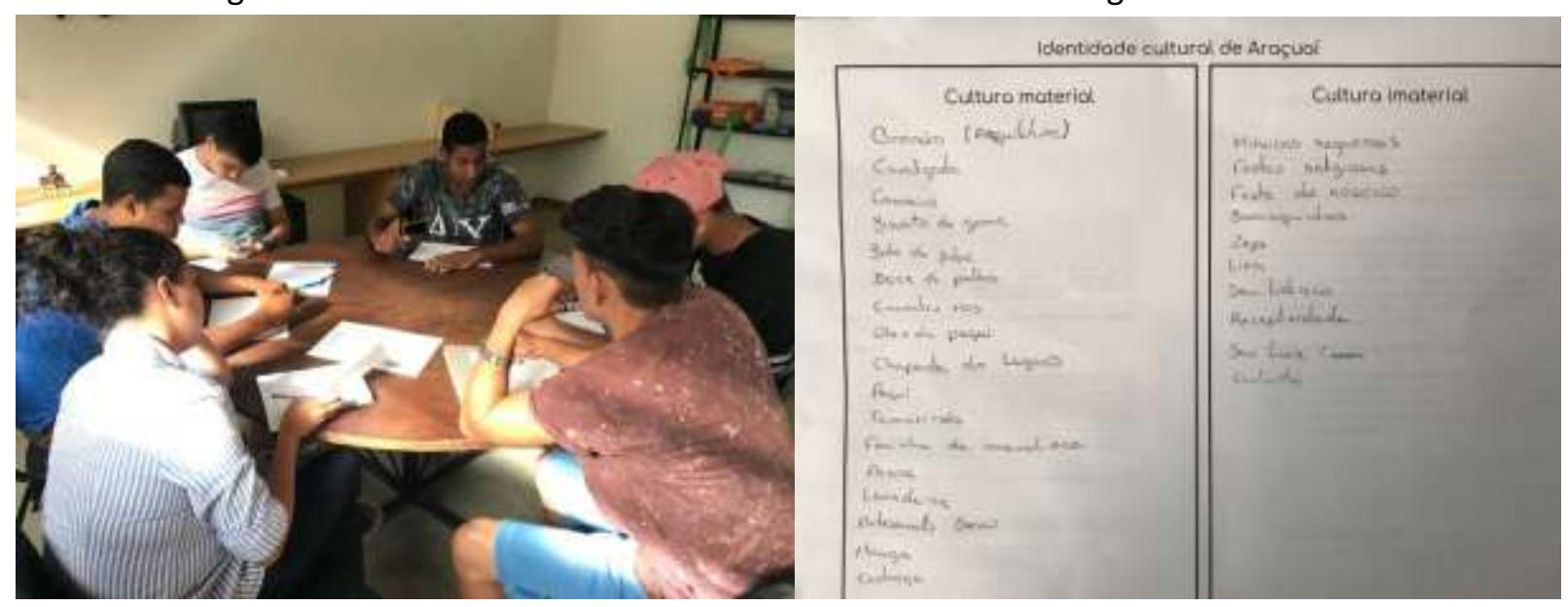

Fonte: Acervo da pesquisa (2018).

Em seguida desenvolveu-se a atividade voltada para a criação dos novos produtos com os participantes. Os artesãos tanto da fabriqueta "Tintas de Terra" como também da fabriqueta "Arte em madeira" se reuniram para pensarem juntos sobre os produtos que iriam desenvolver como resultado das oficinas. Os mesmos decidiram que seria interessante realizar uma linha de produtos no qual os produtos conversassem entre si e teriam a mesma "linha" de inspiração. Eles também discutiram como a cultura material e imaterial da cidade poderia expressar-se nos produtos e alguns pontos interessantes foram levantados, como: desenhos, formato dos produtos, texturas, o uso de cores, mistura de matérias-primas, entre outros.

\subsection{Expedição Fotográfica}

Esta atividade constitui-se em observação, reconhecimento da cultura e dos elementos da identidade local, em um roteiro por vários pontos de uso público com os participantes do projeto. Essa percepção é contextualizada em registro fotográfico de suas singularidades, "trabalhando o olhar" como exercício para o desenvolvimento de novos produtos. Os locais escolhidos para

http://portal.iphan.gov.br/pagina/detalhes/276

http://portal.iphan.gov.br/pagina/detalhes/234 
visitação foram: a ponte do Rio Araçuaí, mercado municipal e arredores, monumento da arara, mirante, Praça Santa Teresa, Praça do Coreto, antigo prédio da prefeitura, centro antigo e a rua de baixo. A expedição durou cerca de duas horas e meia e foi coletado ao todo mais de 400 imagens da cidade. Os artesãos fotografaram as paisagens naturais como o rio Araçuaí, animais, vegetação, flores e chapadas; pessoas em seus locais de trabalho como o carroceiro, vendedor do fumo e o feirante; casarões, casebres e igrejas; comidas e bebidas típicas; monumentos diversos, artesanato local e objetos do cotidiano (Fig. 05 e 06).

Figura 05 e 06 : Artesãos durante a expedição fotográfica.

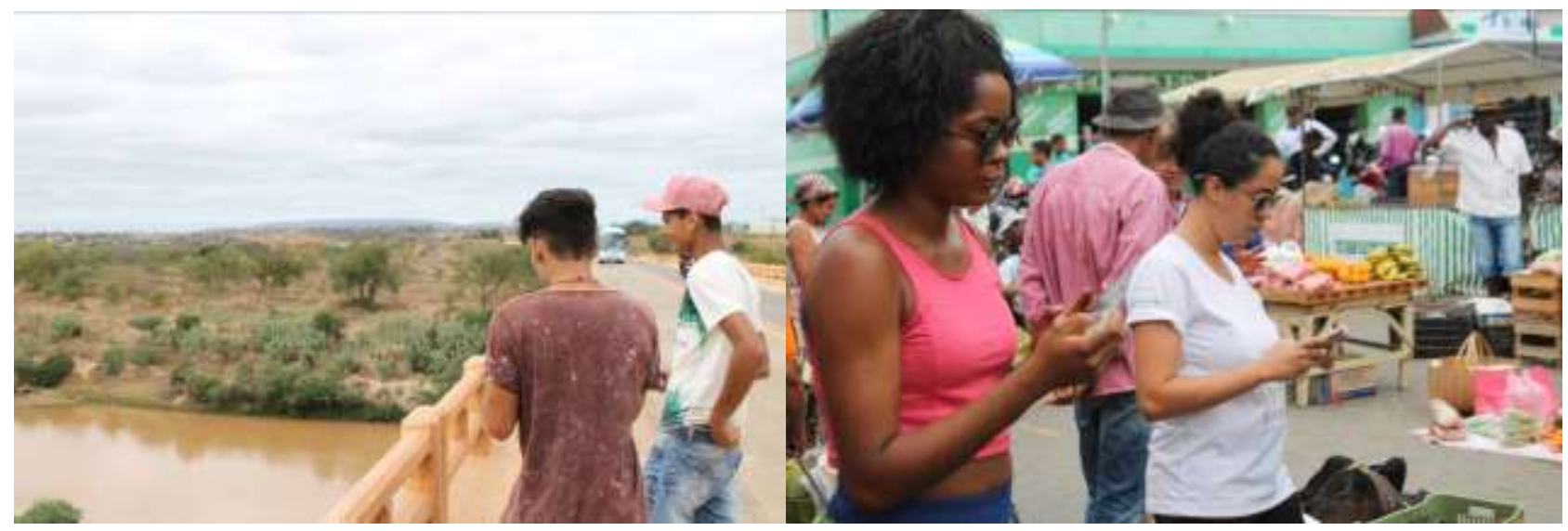

Fonte: Acervo da pesquisa (2018).

A conclusão dessa atividade ocorre no retorno a sede da cooperativa, na compilação dos registros fotográficos de todos os participantes para o computador de uso comum. Em seguida, as fotos foram impressas para montagem de painéis. Os painéis seguiram a orientação de agrupamento de fotos de acordo com semelhanças, nomeando cada grupo identificado. Este trabalho, posteriormente serviria de inspiração e referência para o desenvolvimento dos novos produtos (fig. 07). Todos estavam entusiasmados durante toda a expedição fotográfica e na conclusão da atividade em painéis. Diversos comentários foram registrados pela pesquisadora nesta atividade. Alguns dos participantes não transitavam a muito tempo pelos locais escolhidos e ficaram surpresos com tantas referências encontradas. Outros, sempre passaram pelos locais da expedição, mas não observavam com o olhar de turista. Assim, registram-se que há cheiros diferentes, cores predominantes, objetos da cultura local, formas e texturas, pessoas e costumes tradicionais, que muitas vezes passam despercebidos. 
Figura 07: Painéis de referência com as fotos tiradas durante a expedição fotográfica.

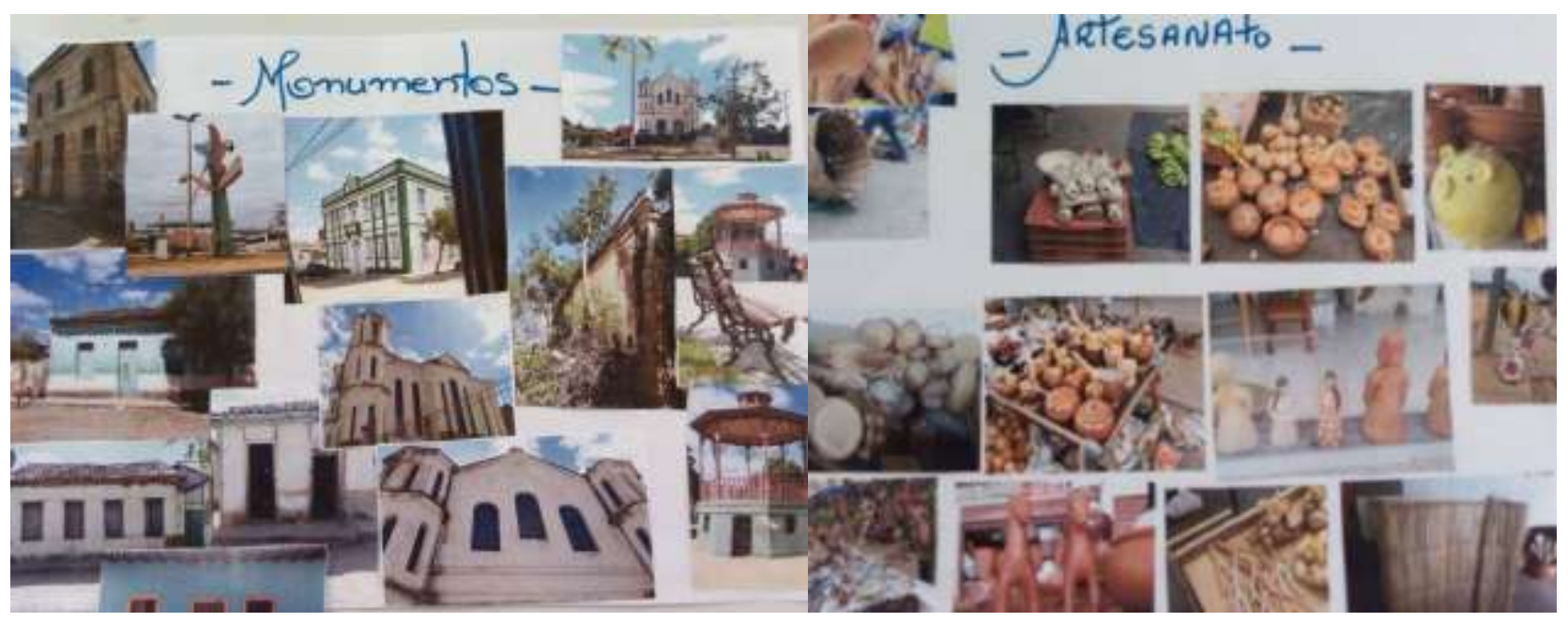

Fonte: Acervo da pesquisa (2018).

\subsection{Oficina de Criatividade}

O processo de desenvolvimento desta oficina, inicia-se pelo debate sobre o conhecimento da criatividade. Os artesãos se manifestaram dizendo que a palavra estava associada a invenção, inovação e a criar algo diferente. A partir de então, a pesquisadora trouxe a definição da palavra segundo o dicionário Aurélio que define a palavra como "1. qualidade ou característica de quem ou do que é criativo. 2. inventividade, inteligência e talento, natos ou adquiridos, para criar, inventar, inovar, quer no campo artístico, quer no científico, esportivo etc.".

Em seguida, foi questionado aos artesãos, se eles acreditavam que a criatividade era algo nato, um talento que nasce com a pessoa? Eles não souberam ao certo responder a esta pergunta. Apresentou-se visão de Thomas Edson sobre a criatividade. O inventor acredita que a criatividade seja como uma musculatura humana, desenvolve - se a medida em que é estimulada, considerando, portanto, que qualquer um tem a capacidade de ser criativo em qualquer campo do conhecimento.

Durante o encontro também foi discutido que nem sempre a criação de um produto significa criar algo totalmente novo. Levou-se a saber que alguns projetos partem de produtos que já existem e propõem novas formas, funções e usos que podem transformá-lo em um produto melhor para o consumidor. Foram apresentados alguns exemplos de produtos que passaram por este processo, como por exemplo o telefone fixo e o celular.

Após a apresentação foi proposto uma atividade chamada Desafio do Marshmallon. Esta atividade foi criada por Tom Wujeck, designer da Autodesk e já foi aplicada em cerca de 70 países. O objetivo desta atividade consiste em encorajar uma equipe a vivenciar lições simples, mas profundas em planejamento, inovação e criatividade. Os artesãos tinham como desafio criar a torre mais alta possível utilizando - se apenas de 20 macarrões crus, fita crepe e barbante (Fig. 08 e 09). No topo da torre deveria conter um marshmallon inteiro.

Os participantes formam divididos em 2 grupos, todas as regras foram lidas e disponibilizado 3 minutos para a fase de planejamento (lápis e papel foram oferecidos nesta etapa) e 18 minutos para a fase de execução. Os artesãos finalizaram a fase de planejamento em 1 minuto e meio e esboçaram apenas o primeiro e único desenho de como seria a torre. A partir de então iniciou-se a construção da torre. 
Figura 08 e 09: Artesãos durante atividade do Desafio do Marshmallon.

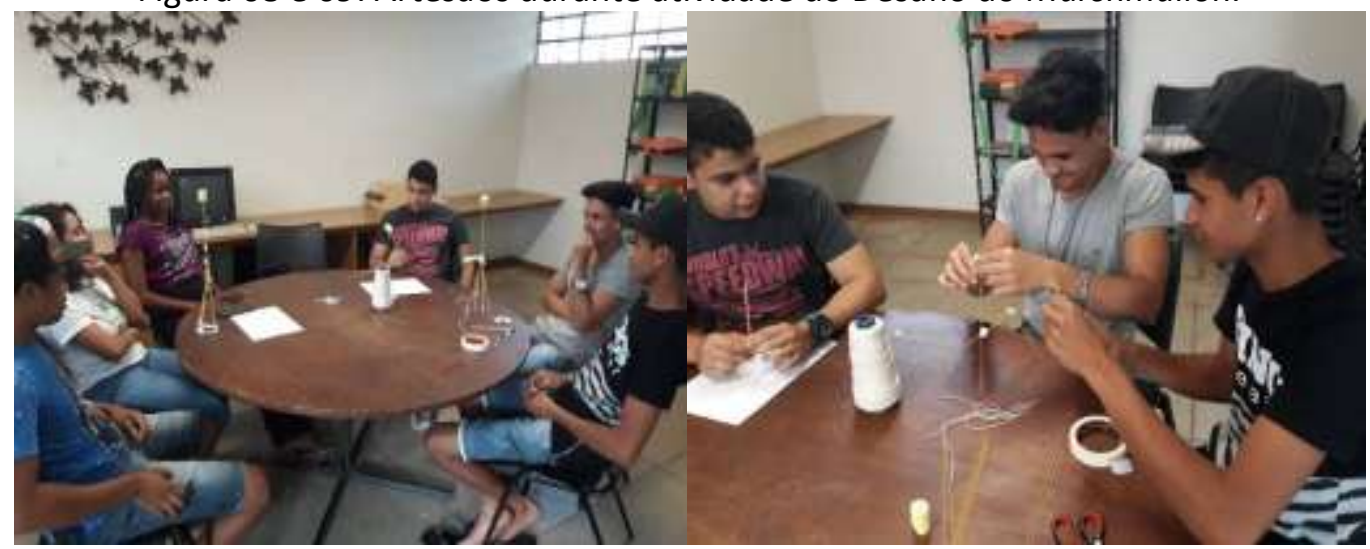

Fonte: Acervo da pesquisa (2018).

A após o término do tempo os dois grupos conseguiram finalizar a atividade e as torres foram medidas $(53 \mathrm{~cm}$ e $48 \mathrm{~cm}$ ). Após o exercício passamos para um momento de reflexão sobre a atividade. Pedi primeiramente para que os artesãos analisassem se o que foi planejado foi realmente o que eles executaram, em seguida perguntei o que tinha dado certo e o que tinha dado errado. Os próprios artesãos perceberam que o planejado não foi o executado e que foi dedicado pouco tempo para a fase de planejamento.

Contudo, foi explicado aos participantes a importância da etapa de planejamento, o cuidado que se deve ter ao pensar, analisar, na busca pela melhor alternativa possível para o desenvolvimento de um produto ou de uma solução. Apresentou-se exemplos desta mesma atividade quando é aplicada em crianças do jardim de infância, onde elas conseguem fazer torres mais altas do que qualquer outro grupo de pessoas e buscou-se refletir o porquê crianças tiveram mais sucesso durante a construção das torres do que eles. A pesquisadora expôs que as crianças têm a mente mais aberta, criativa e sem bloqueios, por isso desenvolvem esta atividade mais facilmente. Finalizando esta etapa, os artesãos iniciaram os primeiros esboços dos novos produtos a serem desenvolvidos a partir de inspirações dos painéis de referência que foram confeccionados no último encontro.

\section{Análises e considerações}

O design, como um modelo de atividade criativa e inovadora, pode contribuir com o desenvolvimento de uma comunidade, à medida que se envolve com o sistema de produção local. Ele pode utilizar de características locais que transponham ao produto a riqueza de novos detalhes e composições, que atribuem a beleza singular, dotada de símbolos e representações únicas da região. É preciso, no entanto, que o designer assuma o desafio de traduzir e interpretar as características da cultura local, de forma correta, e ter sensibilidade para percebê-las como fator diferencial e competitivo, sem interferir no seu real significado. Além disso, deve-se promover a identidade da localidade, que transmite ao mundo a localização da origem do produto.

O artesanato é uma atividade consolidada pelos benefícios sociais, que envolve a participação do artesão e da comunidade onde o processo de produção se realiza. Além de promover a geração de renda, o artesanato proporciona uma satisfação pessoal ao artesão. Observa-se que o núcleo familiar é, na maioria das vezes, participante do sistema de produção, direta ou indiretamente.

Dessa forma aponta-se a dedo de Gente, uma cooperativa que envolve a produção artesanal de jovens da comunidade. A Cooperativa Dedo de Gente de Araçuaí promove práticas sociais eficazes no enfrentamento de questões comunitárias, diante à ausência ou deficiência das 
políticas públicas implantadas na região. Esta organização vem se consolidando como modelo de gestão e participação comunitária ao terceiro setor, no sentido de apresentar um processo histórico de acúmulo de práticas e experiências de efetivas.

O desenvolvimento das Oficinas de Design e Artesanato foi uma atividade inserida em projeto de pesquisa que exerceu um impacto significativo no sistema de produção da fabriqueta de resíduos de madeira, da Cooperativa Dedo de Gente, em Araçuaí. Durante o processo de formação dos alunos participantes foi observado uma mudança de comportamento em relação ao conhecimento de métodos em design e ao saber olhar e reconhecer o ambiente ao entorno. Percebeu-se inclusive, que as atividades da Oficina de Identidade, cultura material e imaterial proporcionaram conhecimentos do território, aos quais os alunos não davam valor. É comum em comunidades interioranas a valorização da estética de outros povos, instituída pelos meios de comunicação, ao invés de potencializar o cerne da comunidade local em seus produtos. Essa mesma indagação foi percebida durante a Oficina de Expedição Fotográfica, onde os participantes descobriram (com outro olhar) as praças, o mercado, a estação, enfim, a cidade de Araçuaí.

A conclusão da oficina em processo criativo apresentou, na criação de novos produtos, que as metodologias criadas e adotadas evidenciam inovação, além de congregar e revelar aspectos socialmente relevantes da comunidade de Araçuaí.

\section{Referências}

BORGES, A. Designer não é Personal Trainer e outros escritos. 2 ed. São Paulo: Edições Rosari. 2003.

. Design + artesanato: o caminho brasileiro. São Paulo: Editora Terceiro Nome, 2011.

CANCLINI, N. G. Culturas Híbridas: estratégias para entrar e sair da modernidade. Trad. Heloísa Pezza Cintrão, Ana Regina Lessa. 3. ed. - São Paulo: Editora da Universidade de São Paulo, 2000

CAVALCANTI, Virgínia; ANDRADE, Ana Maria; SILVA, Germannya. Design, sustentabilidade e artesanato: reflexões e práticas metodológicas. Cadernos de Estudos Avançados em design: Sustentabilidade I. Org.: Dijon de Moraes e Lia Krucken. 2 Ed. Barbacena: EdUEMG, 2013.

CROCCO, Heloísa. Artesanato e Design, História de uma Convergência. Arcdesign, São Paulo, n.13, p. 26-29, jul/ago. 2000.

DEDO DE GENTE. Disponível em: <http://www.cpcd.org.br/portfolio/dedo-de-gente-exemplo-dedesenvolvimento-coletivo/>. Acesso em: 08 abr. 2019.

DENIS, Rafael Cardoso. Uma Introdução à História do Design. São Paulo: Edgard Blucher, 2000.

ENGLER, R. ; FREITAS, A. ; KRUCKEN, L. ; CAMPOS, R. Design Participativo: uma experiência no Vale do Jequitinhonha. 1o edição, Belo horizonte, Editora: EdUEMG, 2010.

ENGLER, Rita de Castro; MOURÃO, Nadja Maria; "Design, artesanato e empreendimentos criativos: caminhos para sustentabilidade", p. 307 -324. In: OLIVEIRA, Alfredo Jefferson de; FRANZATO, Carlo; GAUDIO, Chiara Del. Ecovisões projetuais: pesquisas em design e sustentabilidade no Brasil. São Paulo: Blucher, 2017.

FRANÇA, R. A. Design e artesanato: uma proposta social. Revista Design em Foco, vol. II, núm. 2, julho-dezembro, 2005, pp. 9-15.

GODOY, Arilda Schmidt. Introdução a Pesquisa Qualitativa e sua Possibilidades. Revista de Administração de Empresas São Paulo, v. 35, n. 2, p. 57-63. 1995.

MANZINI, E.; MERONI, A. Emerging user demands for sustainable solutions, EMUDE. In MICHAEL, R. (Ed.). Design research now: essays and selected projects. Basel: Birkhäuser, 2007. p. 157-179. 
MANZINI, E. (org.). Design para a Inovação Social e Sustentabilidade: Comunidades Criativas, Organizações Colaborativas e Novas Redes Projetuais. Rio de Janeiro: e-Papers, 2008.

MOURÃO, Nadja. Sustentabilidade com resíduos vegetais na produção artesanal: uma prática de design sistêmico em Chapada Gaúcha. Pensamentos em Design: aspectos tangíveis e intangíveis da pesquisa. Belo Horizonte. 2013.

MOURÃO, Nadja; MARTINS, Daniela. Sabores e Saberes das Geraes: Uma abordagem em Food Design. Org. Rita de Castro Engler. Editora: EdUEMG, Barbacena, 2014.

NIEMEYER, L. Elementos de semiótica aplicados ao design. Rio de Janeiro: 2AB, 2007.

PAZMINO, Ana Verónica. Uma reflexão sobre Design Social, Eco Design e Design Sustentável. I Simpósio Brasileiro de Design Sustentável. Curitiba, p. 4-6, 2007.

SEBRAE. Quer investir no Artesanato? Saiba mais sobre esse mercado.Postado em: 13 mar. 2019. Disponível em: <www.sebrae.com.br/sites/PortalSebrae/ufs/ms/artigos/boletim-comercio-eservicos-artesanato, afb621600576a410VgnVCM1000003b74010aRCRD >.Acesso em: 08 abr. 2019. . Programa Sebrae de Artesanato: Termo de Referência. São Paulo, 2004.

SMITH, Adam. A Riqueza das Nações. Trad. Alexandre Amaral Rodrigues e Eunice Ostrensky, São Paulo: Martins Fontes, 1a ed., 2003.

SOUZA, R.E. Design e comunicação: estratégias para o mercado artesanal. Anais do 50 ENP Moda, Novo Hamburgo: Editora Fevale, v. 5, 2015. 